\title{
Cholinergic effects on human gastric motility
}

\author{
H P Parkman, D M Trate, L C Knight, K L Brown, A H Maurer, R S Fisher
}

\begin{abstract}
Background-Cholinergic regulation of chronotropic (frequency) and inotropic (force) aspects of antral contractility and how these impact on gastric emptying are not well delineated.

Aims-To determine the effects of cholinergic stimulation and inhibition on myoelectric, contractile, and emptying parameters of gastric motility.

Methods-Ten normal subjects underwent three studies each, using simultaneous electrogastrography (EGG), antroduodenal manometry, and gastric emptying with dynamic antral scintigraphy (DAS). After 30 minutes of baseline fasting manometry and EGG, subjects received saline intravenously, atropine $(0.6 \mathrm{mg}$ then 0.25 mg/hour intravenously), or bethanechol (5 mg subcutaneously). This was followed by another 30 minutes' recording and by three hours of postprandial recording after ingestion of a technetium-99m labelled solid meal.
\end{abstract}

Results-During fasting, atropine decreased, whereas bethanechol increased, the antral manometric motility index and EGG power. Postprandially, atropine decreased the amplitude of antral contractions by DAS, decreased the postprandial antral manometric motility index, and slowed gastric emptying. Atropine caused a slight increase in postprandial frequency of antral contractions by DAS and gastric myoelectrical activity by EGG. Bethanechol slightly increased the amplitude, but slightly decreased the frequency of antral contractions by DAS and decreased the frequency of gastric myoelectrical activity by EGG, with no significant increase in the motility index or gastric emptying.

Conclusions-Cholinergic antagonism with atropine reduces antral contractility and slows gastric emptying. Cholinergic stimulation with bethanechol increases antral contractility, but decreases the frequency of antral contractions, without altering the antral motility index or gastric emptying.

(Gut 1999;45:346-354)

Keywords: atropine; bethanechol; gastric motility; gastric scintigraphy; electrogastrography

Dr

Gastroenterology Section,

Department of Medicine,

Parkinson Pavilion, 8th

Floor, Temple University

School of Medicine, 3401

North Broad Street,

Philadelphia, PA 19140,

USA.

Accepted for publication 9 March 1999

The overall effects of cholinergic agents on the regulation of gastric contractility and emptying are not well delineated. Cholinergic antagonists, such as atropine, have been shown to decrease antral contractility and slow gastric emptying. ${ }^{12}$ Cholinergic agonists, such as bethanechol, have been reported to increase antral contractility. ${ }^{34}$ Although there are some conflicting reports, bethanechol seems to have little effect on overall gastric emptying. ${ }^{56}$ These prior studies have usually measured only one aspect of gastric motility, such as gastric emptying or antral contractions. Gastric emptying is regulated by many mechanisms including gastric myoelectric and contractile activity. ${ }^{7}$ In addition, efficient gastric emptying requires coordination between the proximal and distal stomach. Little is known about cholinergic regulation of regional gastric emptying, namely emptying from the proximal versus distal stomach. Furthermore, little is known about the cholinergic regulation of the chronotropic (frequency) or inotropic (force) aspects of antral contractility and how these relate to gastric emptying. The aim of this study was to investigate cholinergic effects on gastric motility by studying the effects of the cholinergic antagonist, atropine, and the cholinergic agonist, bethanechol, using simultaneous measurement of gastric myoelectric activity, antral contractility, and regional gastric emptying.

\section{Methods}

Ten normal volunteers were studied on three separate days using a three way crossover design comparing the effects of placebo, atropine, and bethanechol on gastric motility. On each study day, subjects underwent simultaneous antroduodenal manometry (ADM), cutaneous electrogastrography (EGG), and gastric emptying (GE) with dynamic antral scintigraphy (DAS). This protocol was approved by the Institutional Review Board and Radiation Protection Committees of Temple University Hospital.

\section{STUDY SUBJECTS}

Ten normal men were recruited for this project (mean age 32 years, range 25-43). Potential study subjects were initially screened by telephone, and subsequently underwent a medical history and physical examination. Exclusion criteria included prior gastrointestinal surgery (except appendectomy), the presence or history of gastro-oesophageal reflux, peptic ulcer disease, irritable bowel syndrome, chronic gastrointestinal symptoms, or the use of any medications that might affect gastrointestinal motility.

\section{STUDY PROTOCOL}

Enrolled subjects were instructed to begin fasting at $10 \mathrm{pm}$ on the night prior to the study
Abbreviations used in this paper: $\mathrm{ADM}$, antroduodenal manometry; DAS, dynamic antral Fourier transform; GE, gastric emptying; LAO, left anterior oblique; MI, motility index. scintigraphy; EGG, electrogastrography; FFT, fast 
An antroduodenal manometry catheter was advanced transnasally to the ligament of Treitz (see below). Cutaneous EGG electrodes were placed (see below). The recordings were performed in the Clinical Research Centre of Temple University Hospital with the patient sitting in a hospital bed at a 30 degree angle in order to minimise motion artefacts. The study day protocol included an initial 30 minute recording of fasting antroduodenal manometry and EGG prior to infusion of study drug. Each subject then received in random order on separate days: placebo (normal saline, $5 \mathrm{ml}$ intravenous bolus, then $50 \mathrm{ml} / \mathrm{h}$ intravenously), atropine $(0.6 \mathrm{mg}$ intravenous bolus, then 0.25 $\mathrm{mg} / \mathrm{h}$ intravenously), or bethanechol (5 mg subcutaneous injection, then normal saline 50 $\mathrm{ml} / \mathrm{h}$ intravenously). These doses of atropine and bethanechol were chosen based on prior studies that have shown cholinergic effects of these agents. ${ }^{289}$ The infusion of the study drug was not administered according to a particular phase of the migrating motor complex.

After infusion of the intravenous bolus doses or subcutaneous injections of test agents, fasting antroduodenal manometry and EGG recordings were continued for another $30 \mathrm{~min}$ utes. Each subject then ingested a technetium$99 \mathrm{~m}$ sulphur colloid labelled solid meal with $300 \mathrm{ml}$ unlabelled water (see below). Three hours of postprandial recordings were then obtained using simultaneous ADM, cutaneous EGG, and GE with DAS. Static gamma camera images were obtained every 10-15 minutes to measure solid phase gastric emptying. Each static image was followed by dynamic, one second images for 256 seconds for DAS which was synchronised with antral manometry and EGG recording.

At the end of the study day, a repeat fluoroscopic verification of manometry tube position was obtained, followed by removal of the manometry tube and EGG electrodes.

\section{Antroduodenal manometry}

An antroduodenal manometry catheter containing six solid state pressure transducers was used for these studies (Konigsberg Instruments, Inc., Pasadena, California, USA). The three proximal transducers were $2 \mathrm{~cm}$ apart and the distal three transducers were $10 \mathrm{~cm}$ apart. ${ }^{1011}$ The catheter was passed by nasal intubation into the stomach and positioned fluoroscopically through the pylorus into the duodenum so that the three proximal transducers were located in the distal antrum and the distal tip of the catheter, usually at the ligament of Treitz. Antral and small bowel motility were recorded with a microDigitrapper (Synectics Medical, Inc., Irving, Texas, USA).

\section{EGG recording}

Electrogastrography was performed as previously described. ${ }^{11}$ After placement of the antroduodenal manometry catheter, the abdominal skin surface for each recording site was carefully abraded until slightly erythematous (Buf-Puf Regular; 3M Personal Care Products, St Paul, Minnesota, USA). If abdominal hair was present, it was removed with a razor. Three surface electrodes (Cleartrace electrodes; Medtronic Andover Medical, Inc., Haverhill, Massachusetts, USA) were placed on the abdominal surface overlying the stomach. Two active electrodes were used: one electrode was placed on the midline of the abdomen, halfway between the umbilicus and the xiphoid process; the other was placed on the subject's left side, 1 $\mathrm{cm}$ below the bottom rib and one quarter of the distance towards the ventral midline. A reference electrode was placed on the left lower abdomen, below the umbilicus, equidistant between each active electrode. Gastric myoelectric activity was recorded using the same Synectics microDigitrapper (Synectics Medical) as was used for antroduodenal manometry thus data were acquired simultaneously. The sampling frequency for digital EGG recording was set at $4 \mathrm{~Hz}$.

\section{Gastric and dynamic antral scintigraphy}

Gastric scintigraphy was performed as previously reported ${ }^{11} 1314$ with several modifications. ${ }^{15}$ Solid phase gastric emptying was evaluated after ingestion of a standardised test meal consisting of a ${ }^{99 \mathrm{~m}} \mathrm{Tc}$ sulphur colloid labelled egg sandwich (two large beaten eggs mixed with $74 \mathrm{MBq}(2 \mathrm{mCi}){ }^{99 \mathrm{~m}} \mathrm{Tc}$ sulphur colloid, cooked on a Teflon non-stick griddle until firm and served between two pieces of toasted bread) with $300 \mathrm{ml}$ of unlabelled water. This meal contains $1.18 \mathrm{MJ}$ (32\% protein, $46 \%$ carbohydrate, $22 \%$ fat). Imaging for technetium counts $(128 \times 128$ pixel matrix $)$ using a 140 Kev photopeak with a $20 \%$ window was performed in the left anterior oblique (LAO) projection with the subject's upper body reclining at a 30 degree angle. Images were acquired for 30 seconds each at 10 minute intervals for the first postprandial hour, then every 15 minutes for another two hours using a portable small field of view gamma camera (Datacamera; General Electric Medical Systems, Milwaukee, Wisconsin, USA). The LAO projection was used rather than anterior/ posterior imaging for assessment of gastric emptying as posterior images could not be obtained with the subjects in a hospital bed, in order to minimise movement artefact for the EGG recording. The LAO positioning has been shown to be comparable to anterior/ posterior imaging for depth correction in accounting for the transition as food goes from the posterior fundus to the more anterior antrum. ${ }^{15}$ In addition, after each static acquisition, dynamic acquisition (256 consecutive one second images; $64 \times 64$ pixel matrix) in the anterior projection was recorded to characterise antral contractions. ${ }^{111416}$ The event marker on the microDigitrapper was used to record a time signal at the start of DAS recording to facilitate timing for later analysis of simultaneously acquired DAS, EGG, and ADM.

DATA ANALYSIS

Antroduodenal manometry

After the study was completed, the manometric and EGG data were downloaded from the microDigitrapper to a computer (NEC Powermate SX/25i). For analysis of antral motility, 
the most distal antral lead showing an antral pattern of contractility (high amplitude pressure waves with frequencies of $0-4$ cycles per minute) was used..$^{11}$ The distal small bowel pressure transducer was used for distal duodenal contractility. Postprandial antral and duodenal contractility were quantified as motility indexes, calculated using computer software (Multigram 6.31B2H4; Gastrosoft, Irving, Texas, USA). ${ }^{11}$ Distal antral and duodenal motility indexes were calculated for consecutive 30 minute time periods. This motility index expresses the contractile activity as the natural logarithm of the area under the manometric pressure peaks above a threshold pressure of $9 \mathrm{~mm} \mathrm{Hg}$. The motility indexes (MI) were calculated using the formula: $\mathrm{MI}=$ ln (area under the curve/duration of recording).

\section{Electrogastrography}

EGGs were analysed using computer software (Multigram 6.31B2H4; Synectics Medical) which used fast Fourier transform (FFT) and running spectral analysis, as previously described $^{12}$ with modifications to analyse smaller time periods throughout the study. ${ }^{11}$ Running spectral analysis was used for $15 \mathrm{~min}$ utes before drug infusion and 15 minutes after study drug infusion. Each running spectrum was 4 minutes 16 seconds long, with the next spectrum advancing one minute, giving $3 \mathrm{~min}-$ utes 16 seconds overlap between consecutive spectra. For the postprandial period, the FFT used a 4 minute 16 second spectrum of data starting at the time stamp entered to indicate the simultaneous acquisition of the DAS images. Use of $4 \mathrm{~Hz}$ sampling frequency and 4 minute 16 second intervals for the FFT gives a frequency resolution of $0.23 \mathrm{cpm}$.

The FFT results were expressed as power as a function of frequency, with the dominant frequency defined as the frequency with the highest power. ${ }^{117}$ The dominant slow wave frequency and its power were determined for the fasting period, both before and after study drug infusion, and for each 256 second DAS acquisition time interval. In addition, the postprandial to fasting power ratio - that is, the ratio between the postprandial and fasting (prior to drug infusion) power of the dominant frequency, was computed for each DAS acquisition time interval. An overall mean postprandial EGG power ratio was obtained by averaging the individual power ratios from the time period 0 to 180 minutes.

Gastric and dynamic antral scintigraphy

Gastric emptying was analysed using conventional techniques previously reported. ${ }^{14-16} \mathrm{~A}$ region of interest was manually created to outline the entire stomach. Radioactive counts in the gastric region of interest were corrected for isotope decay and then expressed as a percentage of the maximal counts. Residual percentage ${ }^{99 \mathrm{~m}} \mathrm{Tc}$ counts in the gastric region of interest were plotted against time to obtain time-activity curves. The time to reach $50 \%$ retention $\left(t_{1 / 2}\right)$, the lag phase of the solid meal, and the emptying rate (slope of the terminal portion of the curve) were determined by computerised curve fitting techniques using percentage retention versus time and a modified power exponential function $(\mathrm{y}(\mathrm{t})=100-$ $\left.100\left(1-\mathrm{e}^{-\mathrm{kt}}\right)^{\beta}\right)^{18}$ with a non-linear least squares fitting algorithm (Kaleidagraph 3.04; Synergy Software, Malvern, Pennsylvania, USA) on a Power Macintosh Computer (8100/80AV; Apple Computer, Cupertino, California, USA). The parameters $k$ and $\beta$ were determined from the computer fit and represent the slope of the terminal portion of the emptying curve and its $y$ axis intercept, respectively. Using this modified power exponential function, the lag phase is equal to $(\ln \beta) / \mathrm{k} .{ }^{18}$ Using this mathematical definition, the end of the lag phase corresponds to the inflection point of the emptying curve at which the slope becomes constant. ${ }^{18}$

Regional gastric emptying of the proximal and distal stomach was analysed by drawing regions encompassing the proximal and distal portions of the stomach as previously described. ${ }^{19}$ The proximal stomach was taken as the upper third of the stomach. The distal stomach was taken as the area of the stomach excluding the proximal stomach. Each region was outlined manually and decay corrected counts for the proximal and distal stomach were expressed as a percentage of the maximum counts in the total stomach and plotted versus time.

Dynamic antral scintigraphy was analysed by previously reported techniques. ${ }^{11} 141620$ In order to allow for precise outlining of the antrum, each set of dynamic images was first reframed in a single composite image. Three equal size regions of interest were drawn on the horizontal portion of the stomach between the incisura angularis and the pylorus to delineate the proximal, middle, and distal antrum. The time-activity curves generated from proximal, middle, and distal regions of interest in the antrum were then analysed from the dynamic images using a refined Fourier transform to determine the dominant frequency and the amplitude of the antral contractile activity. A baseline restoration and normalisation of the raw antral time activity curves was first performed using a third degree polynomial fit. ${ }^{20}$ This serves to eliminate artefacts due to patient or stomach translational movement and transforms the data to indicate the percentage change in respect to antral mean counts for each time interval. An autocorrelation function was then applied to the normalised antral time activity curves. ${ }^{16}$ This function helps to eliminate background noise and non-periodic events in the defined time interval. The FFT of the autocorrelated data was then obtained to determine the dominant frequency (in contractions per minute) and the amplitude of the dominant frequency in each of the proximal, mid, and distal antral regions of interest. This DAS amplitude represents the percentage variation of the normalised counts at the dominant frequency of antral contractions, and has been used as a non-invasive assessment of antral contractions. ${ }^{141920}$ The overall DAS frequency and amplitude of antral contractions were taken as the average value of the proximal, mid, and distal antrum for each of the 256 


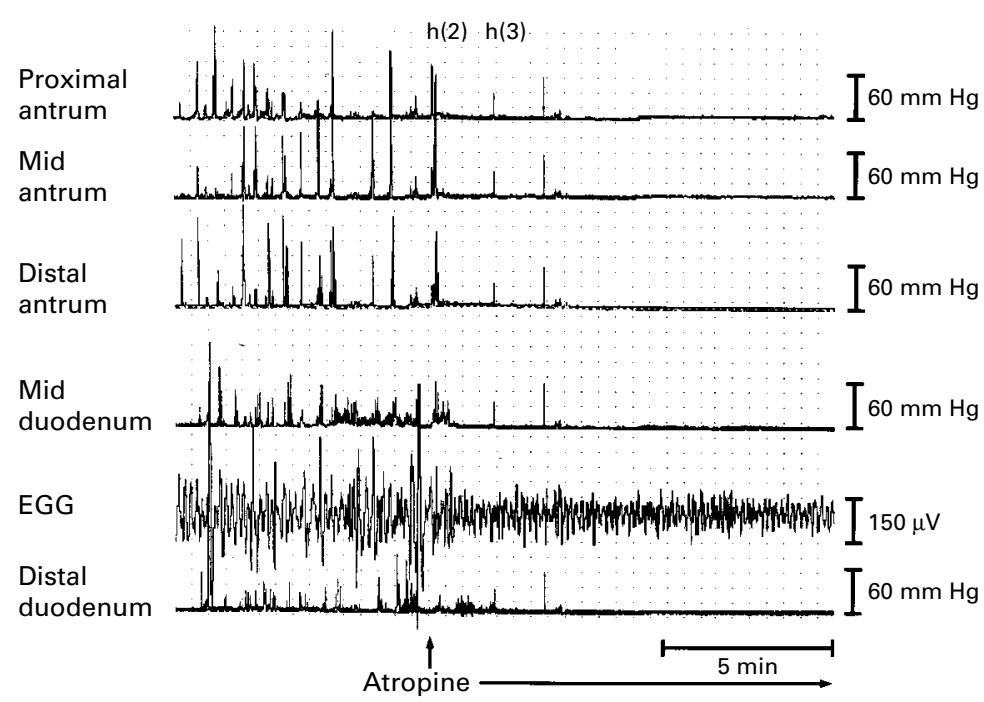

Figure 1 Effect of atropine on fasting antroduodenal manometry and electrogastrography (EGG) recording.

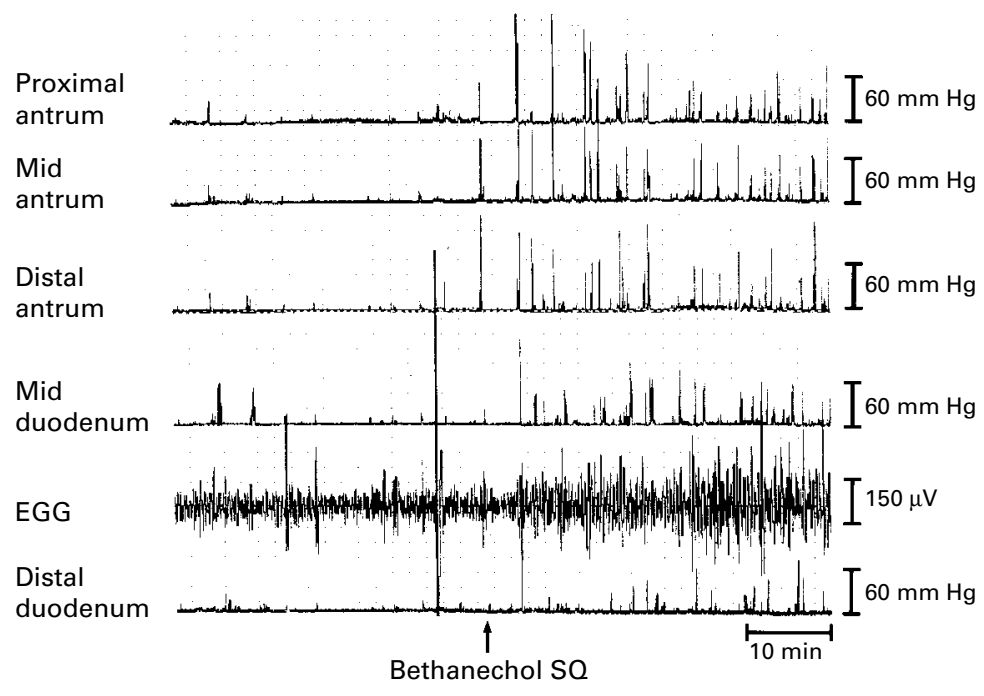

Figure 2 Effect of bethanechol on fasting antroduodenal manometry and electrogastrography (EGG) recording.

second acquisition periods. An overall mean postprandial DAS contractile amplitude was obtained by averaging the individual DAS contractile amplitude from the time period 20 to 150 minutes.

Processing of the static and dynamic data was performed on an 8100 Apple Power PC computer (Apple, Cupertino, California, USA) with applications developed using Kaleida- graph (Abelbeck Software, Pennsylvania, USA) and LabVIEW (National Instruments, Texas, USA) software programs.

\section{STATISTICAL ANALYSIS}

Data are expressed as mean (SEM). The effects of each study drug on each motility parameter were assessed using, where appropriate, $\chi^{2}$ analysis, Wilcoxon signed rank test, analysis of variance, or paired Student's $t$ test with Bonferroni adjustment for repeated measures. These statistical calculations were performed on a Macintosh Performa 6400/180 computer using statistical software (Stat Works; Cricket Software, Inc., Philadelphia, Pennsylvania, USA). Differences were considered statistically significant when the $p$ value was less than 0.05 .

\section{Results}

Of the 10 subjects entered into the protocol, all underwent the placebo and bethanechol studies and nine underwent the atropine study. One subject voluntarily withdrew before his study with atropine.

EFFECTS OF CHOLINERGIC MODULATION ON FASTING ANTRODUODENAL MANOMETRY AND ELECTROGASTROGRAPHY

Figures 1 and 2 show examples of antroduodenal manometry and EGG recording taken during the fasting period. During fasting, atropine decreased antral contractility and decreased the EGG amplitude (fig 1). Bethanechol increased antral contractility and increased the EGG amplitude (fig 2). Overall, there was a decrease in antral manometric motility index and a decrease in EGG power with atropine, whereas there was an increase in antral motility index and EGG power with bethanechol (table 1). Three subjects had transient tachygastria, as recorded by EGG, in the fasting period after atropine infusion; this was not present with placebo or bethanechol administration.

\section{EFFECTS OF CHOLINERGIC MODULATION ON} POSTPRANDIAL ANTRODUODENAL MOTILITY Gastric emptying scintigraphy

Figure 3A shows gastric emptying curves, expressed as percentage retention over time. With atropine, there was significant gastric retention of the meal compared with placebo. Bethanechol had no overall effect on gastric emptying compared with placebo. At two hours after meal ingestion, gastric retention was 34 (3)\% for placebo compared with 73

Table 1 Effect of cholinergic modulation on fasting antroduodenal manometry and electrogastrography

\begin{tabular}{|c|c|c|c|c|c|c|c|c|c|c|c|}
\hline & \multicolumn{5}{|c|}{ Prestudy drug } & \multicolumn{6}{|c|}{ Poststudy drug } \\
\hline & \multicolumn{3}{|c|}{ Antral manometry } & \multirow[b]{2}{*}{$\begin{array}{l}\text { Duodenal MI } \\
\text { (In units) }\end{array}$} & \multirow[b]{2}{*}{$\begin{array}{l}\text { EGG dominant } \\
\text { frequency (cpm) }\end{array}$} & \multicolumn{3}{|c|}{ Antral manometry } & \multirow[b]{2}{*}{$\begin{array}{l}\text { Duodenal MI } \\
\text { (ln units) }\end{array}$} & \multirow[b]{2}{*}{$\begin{array}{l}\text { EGG dominant } \\
\text { frequency (cpm) }\end{array}$} & \multirow[b]{2}{*}{$\begin{array}{l}\text { EGG power } \\
\text { ratio }\end{array}$} \\
\hline & $\begin{array}{l}\text { Frequency } \\
(\text { cpm) }\end{array}$ & $\begin{array}{l}\text { Amplitude } \\
\text { (mm Hg) }\end{array}$ & $\begin{array}{l}\text { MI } \\
\text { (In units) }\end{array}$ & & & $\begin{array}{l}\text { Frequency } \\
(\text { cpm) }\end{array}$ & $\begin{array}{l}\text { Amplitude } \\
\text { (mm Hg) }\end{array}$ & $\begin{array}{l}\text { MI } \\
\text { (ln units) }\end{array}$ & & & \\
\hline Placebo & $1.4(0.3)$ & $29(3)$ & $4.7(0.4)$ & $4.7(0.2)$ & $2.8(0.1)$ & $1.6(0.3)$ & $30(5)$ & $4.8(0.5)$ & $4.2(0.5)$ & $2.7(0.1)$ & $0.95(0.38)$ \\
\hline Atropine & $1.2(0.4)$ & $35(4)$ & $4.9(0.3)$ & $4.5(0.5)$ & $2.8(0.1)$ & $0.3(0.2)^{\star}$ & $10(3)^{\star}$ & $1.5(0.6)^{\star}$ & $2.2(0.7)^{\star}$ & $2.8(0.1)$ & $0.71(0.15)^{\star}$ \\
\hline Bethanechol & $1.3(0.4)$ & $34(8)$ & $4.7(0.5)$ & $3.7(0.7)$ & $2.8(0.1)$ & $1.8(0.2)$ & $39(3)^{\star}$ & $5.6(0.1)^{\star}$ & $4.5(0.3)^{\star}$ & $2.7(0.1)$ & $5.9(2.1)^{\star}$ \\
\hline
\end{tabular}

Results expressed as mean (SEM). ${ }^{\star} \mathrm{p}<0.05$ versus prestudy drug using paired Student's $t$ test.

Electrogastrography (EGG) power ratio in this table is the ratio of the power of the dominant frequency after study drug administration divided by the power of the dominant frequency before study drug administration.

MI, motility index; DAS, dynamic antral scintigraphy. 

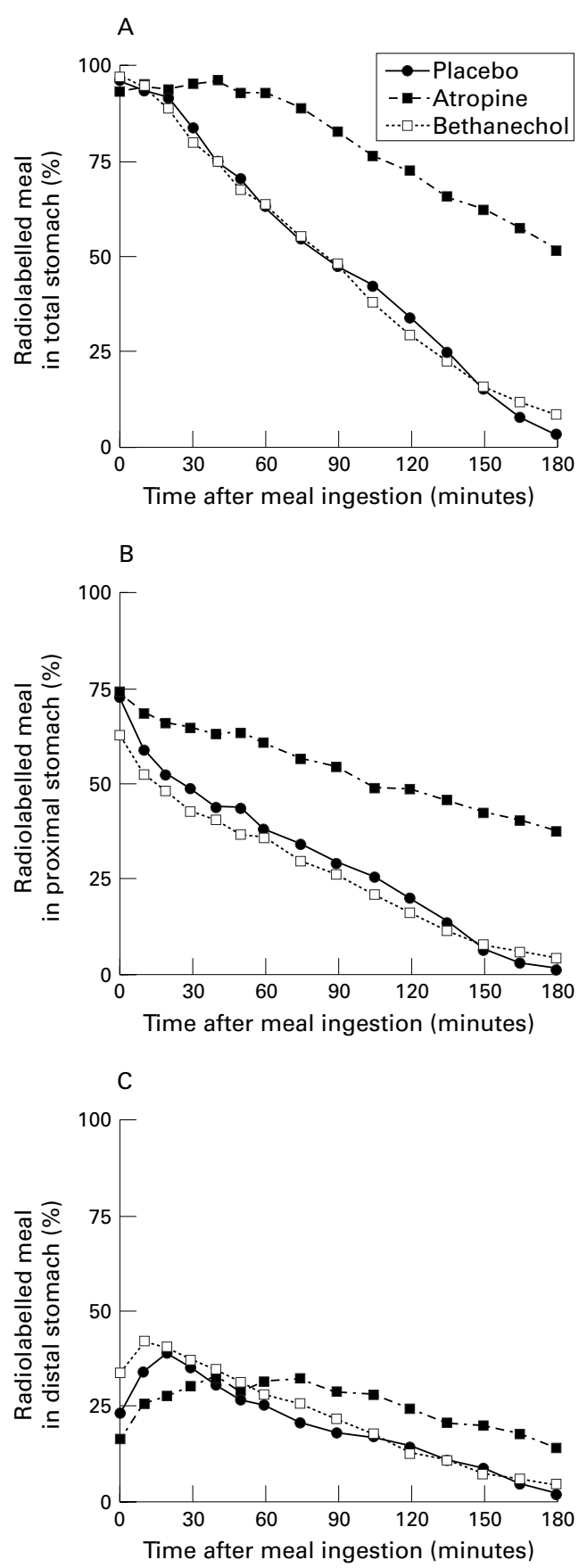

Figure 3 Gastric emptying curves for the total stomach $(A)$, proximal stomach $(B)$, and distal stomach $(C)$.

(4) $\%$ for atropine $(\mathrm{p}<0.01)$ and $29(4) \%$ for bethanechol (table 2). Similarly, the half emptying time for atropine (194 (16) minutes; $\mathrm{p}<0.01$ ) was significantly greater than for placebo (80 (3) minutes), whereas that for bethanechol (80 (5) minutes) was similar to that for placebo (table 2). This delay in gastric

Table 2 Effect of cholinergic modulation on gastric emptying scintigraphy

\begin{tabular}{llccl}
\hline & $\begin{array}{l}\text { \% remaining } \\
\text { at 2 hours }\end{array}$ & $t_{1 / 2}($ min) & Lag phase (min) & Slope $(k)\left(\mathrm{min}^{-1}\right)$ \\
\hline Placebo & $34(3)$ & $80(3)$ & $43(4)$ & $0.016(0.001)$ \\
Atropine & $73(4)^{\star \star}$ & $194(16)^{\star \star}$ & $118(11)^{\star \star}$ & $0.008(0.001)^{\star \star}$ \\
Bethanechol & $29(4)$ & $80(5)$ & $42(5)$ & $0.016(0.002)$
\end{tabular}

Results are expressed as mean (SEM). ${ }^{\star \star} \mathrm{p}<0.01$ versus placebo using ANOVA followed by Student's $t$ test (paired samples; two tailed) with Bonferroni correction factor. emptying for atropine was associated with greater lag phase and a decreased slope of the terminal part of the gastric emptying curve compared with placebo (table 2).

The effect of cholinergic modulation of gastric emptying was further evaluated by analysing regional gastric emptying. Atropine significantly delayed emptying of the radiolabelled meal from the proximal stomach (fig 3B). At 120 minutes, the amount retained in the proximal stomach was significantly greater for atropine $(48(6) \%$ retention; $p<0.01)$ than for placebo $(20(2) \%)$ or bethanechol (16 (3)\%). In contrast, bethanechol tended to have an increased early emptying from the proximal stomach. At the completion of ingestion of the radiolabelled meal (time $t=0$ ), less of the meal was in the proximal stomach for bethanechol (63 (5)\% retention; $\mathrm{p}=0.073$ ) compared with placebo $(73(3) \%)$ or atropine $(74(5) \%)$ (fig 3B).

Figure 3C shows the amount of radiolabelled meal in the distal stomach. This amount in the distal stomach represents the difference of the amount of radiolabelled meal entering the distal stomach from the proximal stomach and the amount of radiolabelled meal emptying from the distal stomach into the duodenum. There were significantly greater amounts of the radiolabelled meal in the distal stomach with atropine compared with placebo, starting 90 minutes after meal ingestion (fig 3C).

\section{Dynamic antral scintigraphy}

The results of the DAS were interpreted only for the 20 to 150 minute postprandial periods due to low counts in the antrum at other times. In the early portion ( $\mathrm{t}=0$ and 10 minutes), not enough counts had arrived in the antrum, and in the later phase ( $\mathrm{t}=165$ and 180 minutes), there were too few counts in the antrum as a result of gastric emptying. Figure 4 shows examples of time activity curves from the mid antral region of interest and Fourier analysis for placebo, atropine, and bethanechol for one subject on different days, each taken 40 minutes after meal ingestion.

Overall, atropine decreased the DAS amplitude of contractions and bethanechol increased the amplitude (table 3 ). With atropine, there was an overall slight increase in frequency of contractions; whereas with bethanechol, there was a significant decrease in frequency (table 3). Thus, there were reciprocal changes in the frequency and amplitude of contractions measured by DAS.

\section{Antroduodenal manometry}

Figure 5 shows recordings of postprandial antroduodenal manometry and electrogastrography. Figure 6 shows the postprandial antral motility indexes over time for each of the treatment groups. This figure shows the antral manometric motility index over the entire study divided into 30 minute periods starting with the two fasting periods (before and after study drug administration) and for six 30 minute periods postprandially. The antral motility index represents the area under the curve, taking into account both frequency and 

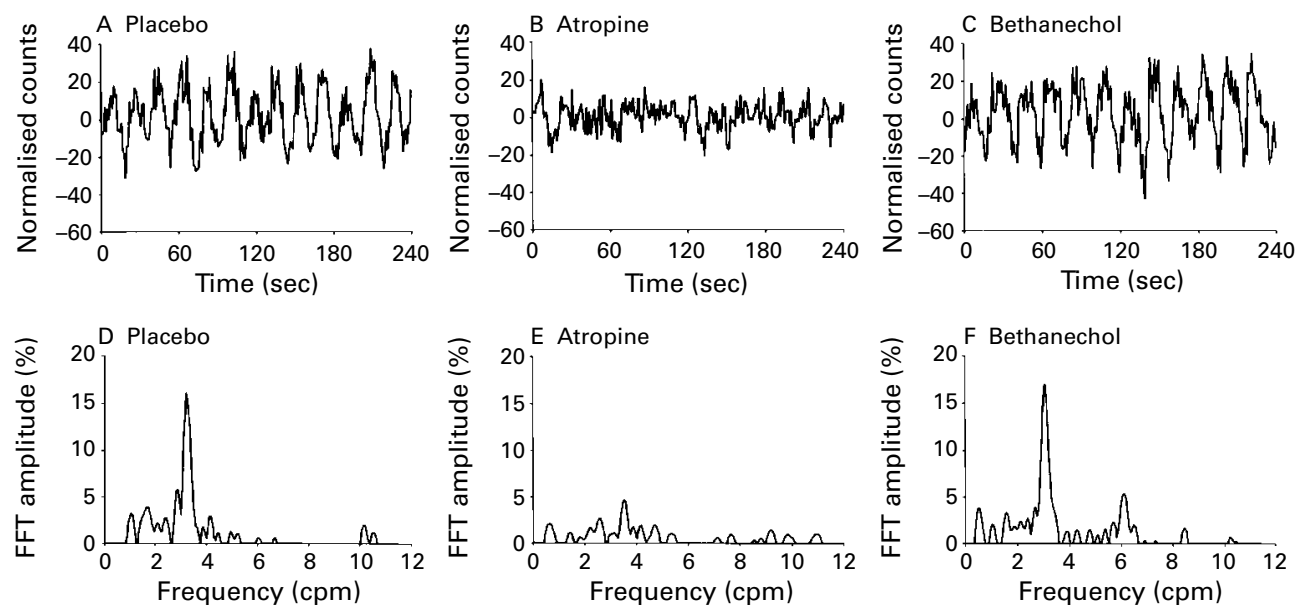

Figure 4 Effect of cholinergic modulation on dynamic antral scintigraphy (DAS). (A-C) The normalised radioactive counts from the mid antrum over a four minute time span for one subject on different days. The phasic counts represent the contracting antrum with the peak counts representing relaxation and the nadir counts representing full contraction. Using a modified fast Fourier transform (FFT), amplitude versus frequency plots were obtained (D-F). The dominant $D A S$ frequency is the frequency with the largest amplitude.

Table 3 Effect of cholinergic modulation on postprandial antroduodenal motility

\begin{tabular}{lllllll}
\hline & $\begin{array}{l}\text { DAS frequency } \\
(\text { cpm })\end{array}$ & $\begin{array}{l}\text { DAS amplitude } \\
(\%)\end{array}$ & $\begin{array}{l}\text { EGG frequency } \\
(\text { cpm })\end{array}$ & $\begin{array}{l}\text { EGG } \\
\text { power ratio }\end{array}$ & Antral MI & Duodenal MI \\
\hline Placebo & $3.43(0.03)$ & $14.7(0.9)$ & $2.93(0.04)$ & $3.2(0.5)$ & $5.3(0.3)$ & $5.0(0.16)$ \\
Atropine & $3.52(0.02)^{\star}$ & $11.0(0.5)^{\star}$ & $3.10(0.01)^{\star}$ & $5.0(0.4)^{\star}$ & $2.4(0.1)^{\star \star}$ & $4.4(0.12)^{\star}$ \\
Bethanechol & $3.19(0.02)^{\star}$ & $16.8(0.5)^{\star}$ & $2.85(0.02)^{\star}$ & $9.7(1.4)^{\star}$ & $5.4(0.2)$ & $5.1(0.1)$ \\
\hline
\end{tabular}

Results expressed as mean (SEM). ${ }^{\star} \mathrm{p}<0.05,{ }^{\star \star} \mathrm{p}<0.01$ versus placebo using ANOVA followed by Student's $t$ test (paired samples; two tailed) with Bonferroni correction factor.

Electrogastrography (EGG) power ratio in this table is the ratio of the power of the dominant frequency after the meal with the study drug divided by the power of the dominant frequency in the fasting period before study drug administration.

MI, motility index; DAS, dynamic antral scintigraphy.

amplitude of antral contractions. With the test meal, there was an increase in antral contractility in the placebo arm compared with the fasting antral motility (see tables 1 and 3 ). This increase was primarily in the first 30 minutes of the postprandial period. (4.8 (0.4) to $6.1(0.2)$; $\mathrm{p}=0.029)$. Atropine notably decreased the postprandial antral motility compared with control, whereas bethanechol did not signifi-

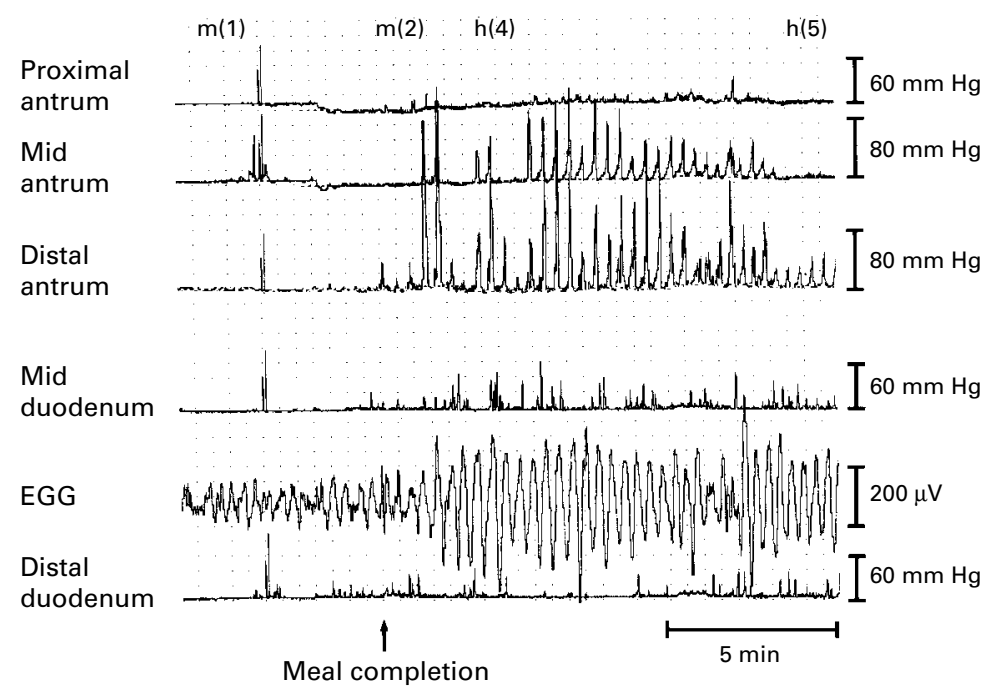

Figure 5 Effect of the test meal on postprandial antroduodenal manometry and electrogastrography (EGG) (placebo arm). cantly change the postprandial motility index compared with control (see fig 6 and table 3 ).

\section{Electrogastrography}

The EGG signals (lead 5 in figs 1, 2, and 5) were analysed for fasting and postprandial time periods by FFT analysis to obtain the dominant frequency and power of the dominant frequency.

There was a transient initial decrease in the EGG dominant frequency seen immediately after meal ingestion. This frequency decrease was similar for the placebo group (2.64 (0.08) $\mathrm{cpm})$ and atropine $(2.61(0.07) \mathrm{cpm})$, but was significantly lower for the bethanechol group (2.34 (0.09) cpm; $\mathrm{p}=0.037)$. Thereafter, similar to the DAS frequency, there was an overall increase in EGG dominant frequency with atropine compared with placebo and a decrease in frequency with bethanechol (fig 7 and table 3).

The postprandial EGG power of the dominant frequency of each study arm is shown in table 3, expressed as a ratio relative to the fasting prestudy drug period. For the placebo arm, the postprandial power ratio is greater than 1, implying an increase of EGG power, or amplitude, after meal ingestion, as seen in fig 5 . Bethanechol, which increased the power in the fasting period (table 1), was associated with a postprandial power ratio above 1 (table 3 ). Atropine, which slightly decreased the fasting 


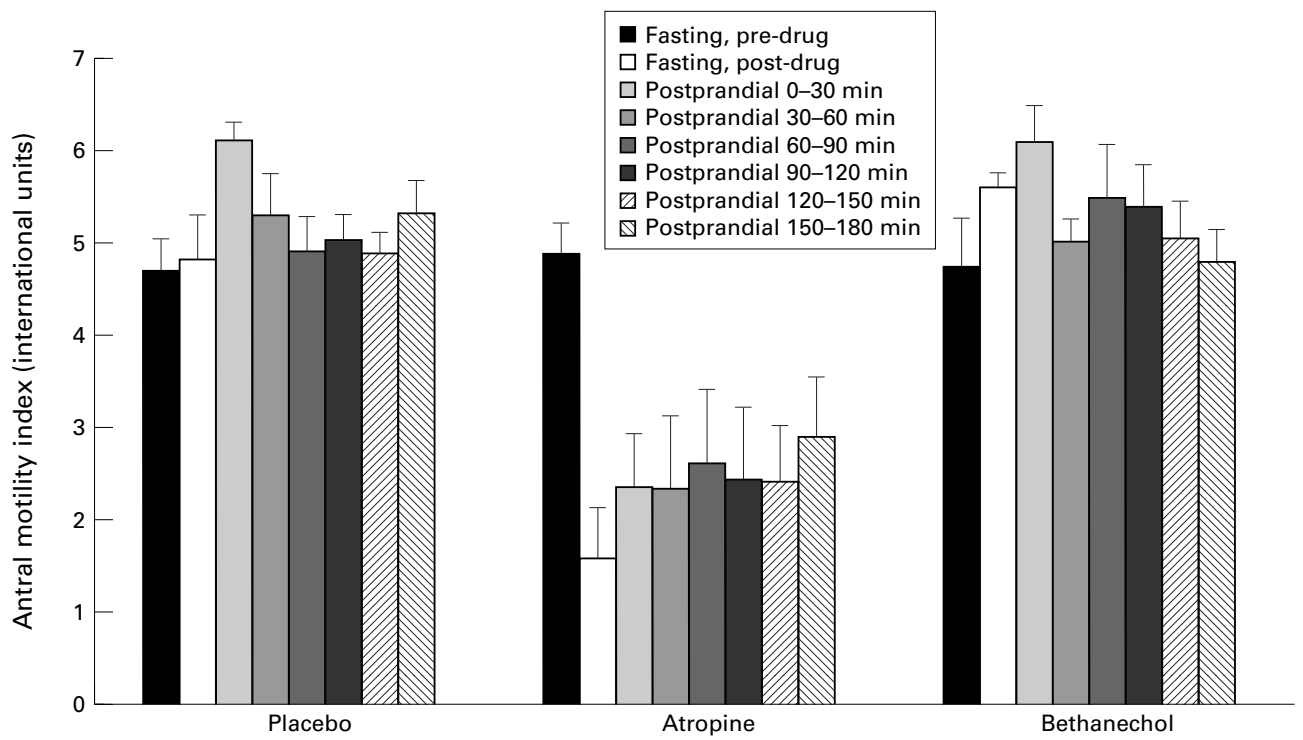

Figure 6 Effect of cholinergic modulation on antral motility index. This index represents the area under the curve taking into account both frequency and amplitude of antral contractions.

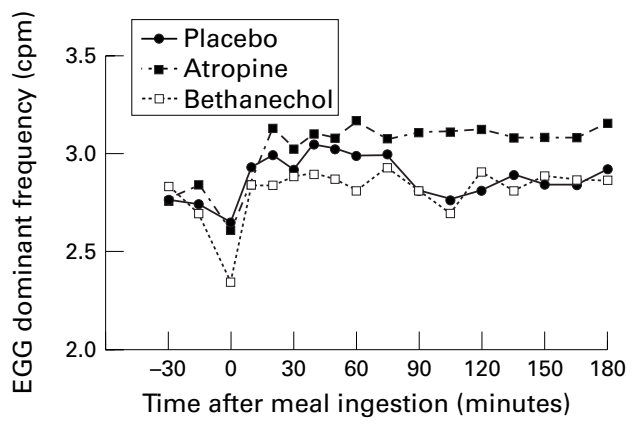

Figure 7 Effect of cholinergic modulation on electrogastrography $(E G G)$ dominant frequency. The initial time point ( $t=-30$ minutes) is the fasting prestudy drug period. The next time point ( $t=-15$ minutes) is the fasting poststudy drug period. Thereafter, the time points are the time after meal ingestion.

power (see table 1), was also associated with a postprandial power ratio above 1 (table 3 ). Both the postprandial power ratios for atropine and bethanechol were significantly greater than the postprandial power ratio for placebo (table 3).

\section{Discussion}

This study shows that cholinergic modulation, with either cholinergic stimulation or cholinergic inhibition, affects gastric motility. In the fasting state, atropine inhibited whereas bethanechol increased antral contractility. In the postprandial state, cholinergic modulation altered gastric emptying by affecting both proximal and distal gastric motility. Both the frequency and the strength of antral contractions were affected. Cholinergic antagonism with atropine reduced antral contractility and notably slowed gastric emptying. Cholinergic stimulation with bethanechol increased antral contractility, and decreased the frequency of antral contractions, such that the antral motility index and gastric emptying were not significantly changed.

In the fasting state, bethanechol increased antral contractility, whereas atropine notably decreased antral contractility. Stimulation of fasting antral and duodenal motility with bethanechol as shown in this study has been reported elsewhere. ${ }^{3421}$ In addition, Katschinski et al further showed that bethanechol, a generalised muscarinic agonist, increased gastric acid and pancreatic enzyme secretion while atropine, a non-specific muscarinic antagonist, reduced antral activity and gastric acid secretion. ${ }^{21}$

The inhibitory effect of atropine on overall gastric emptying has been reported in several studies in normal subjects using liquids, ${ }^{128}$ as well as in diabetic subjects with gastroparesis. ${ }^{3}$ These earlier studies, however, only evaluated total gastric emptying. Whole stomach emptying for solid food is characterised by a biphasic curve consisting of an initial lag phase followed by a constant rate of gastric emptying. ${ }^{18}$ Our analysis of the gastric emptying curve used computer analysis with a modified power exponential to calculate the length of the lag phase and the rate of gastric emptying. Therefore, the gastric emptying process was more fully defined. While there is some controversy on how to calculate the lag phase, ${ }^{15}{ }^{22}$ it generally describes the movement of solid food from the proximal to distal stomach and the time for trituration of solids. With use of the modified power exponential, the lag phase in this study represents the inflection point between the initial portion of the gastric emptying curve with little emptying and the distal portion of the curve with a constant slope. This study used the LAO projection to measure gastric emptying; this may affect the absolute value of lag phase duration, ${ }^{15}$ but should not affect the relative differences between groups in this three way crossover study. Atropine decreased the duration of the lag phase and decreased the terminal rate of gastric emptying, whereas bethanechol had no significant effect on either.

The overall slowing of gastric emptying with atropine was brought about by inhibitory effects on both proximal and distal gastric motor function. In this study, atropine significantly delayed emptying from the proximal 
stomach; this observation is corroborated by other studies that reported a delay in gastric emptying of liquids. ${ }^{2}$ Liquid emptying is primarily dependent on proximal stomach function. ${ }^{23}$ There is also some suggestion in this study that distal gastric emptying is inhibited by atropine due to the increased counts in the distal stomach over time compared with control. However, the counts in the distal stomach depend both on emptying from the distal stomach and delivery from the proximal stomach, the latter of which is clearly delayed by atropine. An inhibition of distal gastric motor function is shown by the decreased strength of antral contractions by DAS and an overall decrease in postprandial contractility by antral manometry.

Interestingly, this study suggests that bethanechol stimulates both proximal and distal stomach contractility despite having no overall apparent effect on global postprandial gastric emptying. There are decreased counts in the proximal stomach at the completion of eating, suggesting that bethanechol may accelerate early gastric emptying from the proximal stomach. These curves were drawn anatomically, with similar areas being used in the three crossover studies for each subject. This increased initial proximal emptying could be achieved by increasing fundic tone or decreasing fundic compliance/accommodation, which were not measured in this study. This could be further studied using a gastric barostat to measure gastric tone directly. Bethanechol has been shown to accelerate liquid gastric emptying in rats. ${ }^{24}$ Using DAS, bethanechol slightly increased the amplitude of antral contractions. Interestingly, there was also a slight decrease in frequency of contractions by DAS. These reciprocal changes in amplitude and frequency of antral contractions with bethanechol could be explained by the electrical excitationcontraction coupling properties of antral smooth muscle. Cholinergic stimulation increases both the amplitude and duration of the antral electrical plateau potential, which increases antral contractile amplitude. ${ }^{25}$ The prolonged duration of the plateau potential with the cellular refractory period may give a resultant decrease in frequency of contractions. These reciprocal changes in frequency and strength of antral contractions, as measured by DAS, probably contribute to the lack of effect on the postprandial antral motility index and no overall change in gastric emptying.

Conflicting changes with the EGG power were observed compared with antral manometry in the assessment of postprandial gastric contractility. In the fasting state, changes in antral contractility are associated with corresponding changes in EGG power: bethanechol increased antral contractility and increased EGG power of the dominant frequency, whereas atropine decreased antral contractility and decreased EGG power. In the postprandial state, the EGG postprandial to fasting power ratio, an indirect measure of signal amplitude, was increased with bethanechol and its associated increased antral contractility. With atropine induced inhibition of antral contractility, there was still an increase in the EGG amplitude, as represented by the postprandial to fasting power ratio of greater than 1 . This is probably due to gastric distension produced by the meal with the atropine induced delayed emptying; gastric distension would bring the intra-abdominal stomach closer to the cutaneous recording EGG electrodes and produce an increased signal amplitude. Thus, this study suggests that the EGG signal amplitude (or power) is affected by both gastric contractility and distension. ${ }^{7}$ Thus, the postprandial EGG amplitude or power may not be an accurate representation of postprandial gastric motility. Recent studies suggest that primarily fundic, rather than antral, distension contributes to increase in EGG power ${ }^{26}$; our study shows significant proximal gastric retention of the test meal, suggesting proximal gastric distension with atropine.

Bethanechol, in this study, did not alter overall gastric emptying. Bethanechol has a direct action on smooth muscle muscarinic receptors. ${ }^{27}$ Its effects are non-specific on muscarinic receptors, as there are side effects from its generalised cholinergic stimulation that include salivation, sweating, and visual changes. ${ }^{28}$ In addition, bethanechol increases gastric acid secretion, ${ }^{21}$ which may indirectly affect gastric emptying. ${ }^{29}$ It is also possible that the reason bethanechol did not produce a significant change in gastric emptying in normal subjects was that the meal itself produced near maximal stimulation of the cholinergic system, as is suggested by the inhibition with atropine, and bethanechol was not able to increase this already present endogenous cholinergic effect.

In gastroparesis, there is delayed gastric emptying due primarily to decreased antral contractility. ${ }^{30}$ As cholinergic stimulation did not accelerate gastric emptying in normal subjects, we speculate that direct cholinergic enhancement of gastric emptying in patients with gastroparesis may also not be feasible. This is tempered by the fact that the strongest effects of prokinetic agents are usually found in patients with delayed emptying, ${ }^{312}$ not, as studied here, in control subjects with normal gastric emptying. However, the inability of bethanechol to accelerate gastric emptying has been shown previously in patients with gastroparesis, ${ }^{6}$ despite other studies that show an increase in antral contractility. ${ }^{34}$

The prokinetic agents, cisapride and metoclopramide, increase cholinergic activity but by a selective neural mechanism, not only by increasing antral contractility, but also by increasing overall antroduodenal coordination. ${ }^{32} 33$ Bethanechol has little effect, if any, on coordinating contractions. ${ }^{33}$ Our results agree with those of other authors who suggest that bethanechol should not be considered a true prokinetic agent as it does not affect overall transit or emptying despite increasing antral contractions. ${ }^{627}$

In conclusion, this study shows that cholinergic modulation, with either cholinergic stimulation or cholinergic inhibition, affects gastric emptying by altering both proximal and 
distal gastric contractility. Cholinergic antagonism with atropine reduces proximal gastric emptying, reduces antral contractility and notably slows gastric emptying. Cholinergic stimulation with bethanechol increases antral contractility, but decreases the frequency of antral contractions, without altering the antral motility index or gastric emptying.

Portions of this study were presented at the 1997 American Gastroenterological Association Meeting and reported in abstract form (Gastroenterology 1997;112:A804). This research was supported in part by the PHS Research Grant M01RR00349 from the General Clinical Research Center Program, NCCR, National Institutes of Health. The authors are gratefu to Dr Jean-Luc Urbain for helping to process some of the dynamic antral scintigraphy data.

1 Chernish SM, Brunelle RR, Rosenak BD, et al. Comparison of the effects of glucagon and atropine sulfate on gastric emptying. Am $\mathcal{f}$ Gastroenterol 1978;70:581-6.

2 Rashid MU, Bateman DN. Effect of intravenous atropine on gastric emptying, paracetamol absorption, salivary flow and heart rate in young and fit elderly volunteers. Br $\mathcal{F}$ Clin Pharmacol 1990;30:25-34.

3 Fox S, Behar J. Pathogenesis of diabetic gastroparesis: a pharmacologic study. Gastroenterology 1980;78:757-63.

4 Malagelada J-R, Rees WDW, Mazzotta LJ, et al. Gastric motor abnormalities in diabetic and postvagotomy gastroparesis: effect of metoclopramide and bethanechol Gastroenterology 1980;78:286-93.

5 Hamilton SG, Sheiner HJ, Quinlan MF. Continuous monitoring of the effect of pentagastrin on gastric emptying of solid food in man. Gut 1976;17:273-9.

6 McCallum RW, Fink SM, Lerner E, et al. Effects of metoclopramide and bethanechol on delayed gastric emptying present in gastroesophageal reflux patients. Gastroenterology 1983;84:1573-7.

7 Parkman HP, Harris AD, Krevsky B, et al. Gastroduodenal motility and dysmotility: update on techniques available for evaluation. Am 7 Gastroenterol 1995;90:869-92.

8 Fisher RS, Rock E, Malmud LS. Cholinergic effects on gallbladder emptying in humans. Gastroenterology 1985;89: b16-22.

9 Koshy S, Woods M, Bennett T, et al. Gastric mechanoreceptor mediation of fed electrogastrographic signal increases by non-cholinergic, non-serotonergic pathways [abstract] by non-cholinergic, non-serc
Dig Dis Sci 1996;41:1883.

10 Holland R, Gallagher MD, Quigley EMM. An evaluation of an ambulatory manometry system in assessment of antroduodenal motor activity. Dig Dis Sci 1996;41:1531-7.

11 Parkman HP, Urbain JL, Knight LC, et al. Effect of gastric acid suppressants on human gastric motility. Gut 1998;42 243-50.

12 Parkman HP, Harris AD, Fisher RS. Influence of age, gender, and menstrual cycle on the normal electrogastrogram. Am 7 Gastroenterol 1996;91:127-33.

13 Knight LC, Parkman HP, Brown KL, et al. Delayed gastric emptying and decreased antral contractility in normal premenopausal women compared with men. Am 7 Gastroenterol 1997;92:968-75.
14 Urbain J-LC, Maurer AH. The stomach. In: Wagner Jr HN, Szabo A, Buchanan JW, eds. Principles of nuclear medicine. Philadelphia: Saunders, 1995:916-29.

15 Maurer AH, Knight LC, Charkes D, et al. Comparison of left anterior oblique and geometric mean gastric emptying. f Nucl Med 1991;32:2176-80.

16 Urbain J-LC, Vekemans MC, Parkman H, et al. Characterization of gastric antral motility in functional dyspepsia using digital antral scintigraphy. 7 Nucl Med 1995;36:157986.

17 Chen JDZ, McCallum RW. Clinical applications of electrogastrography. Am f Gastroenterol 1993;88:1324-36.

18 Siegel JA, Urbain J-L, Adler LP, et al. Biphasic nature of gastric emptying. Gut 1988;29:85-9.

19 Urbain J-L, Siegal JA, Charkes ND, et al. The twocomponent stomach: effects of meal particle size on fundal and antral emptying. Eur $\mathcal{F}$ Nucl Med 1989;15:254-9.

20 Urbain J-LC, Charkes ND. Recent advances in gastric emptying scintigraphy. Semin Nucl Med 1995;25:318-25.

21 Katschinski M, Steinicke C, Reinshagen M, et al. Gastrointestinal motor and secretory responses to cholinergic stimulation in humans. Differential modulation by muscarinic and cholecystokinin receptor blockade. Eur 7 Clin Invest 1995;25:113-22.

22 Maurer AH, Knight LC, Krevsky B. Proper definitions for lag phase in gastric emptying of solid foods. $\mathrm{F} \mathrm{Nucl} \mathrm{Med}$ 1992;33:465-6.

23 Kelly KA. Gastric emptying of liquids and solids: roles of proximal and distal stomach. Am F Physiol 1980;239:G716.

24 Megens AAHP, Awouters RHL, Nermegeers CJE. General pharmacology of the four gastrointestinal motility stimulants bethanechol, metoclopramide, trimebutine, and cisapride. Arzneimittelforschung Drug Res 1991;41:631-4.

25 Szurszewski JH. Electrical basis for gastrointestinal motility. In: Johnson LR, ed. Physiology of the gastrointestinal tract. 2nd edn. New York: Raven Press, 1987:383-422.

26 Ladabaum U, Koshy S, Hooper F, et al. Differential symptoms and electrogastrographic signal amplitude and rhythm responses to gastric antral and fundic mechanoreceptor activation [abstract]. Gastroenterology 1997;112: A769.

27 Reynolds JC, Putnam PE. Prokinetic agents. Gastroenterol Clin North Am 1992;21:567-96.

28 Physicians' desk reference. 49th edn. Montvale, NJ: Medical Economics Data Production Company, 1995.

29 Dubois A, Castell DO. Histamine H2-receptor involvement in the regulation of gastric emptying. $A m \mathcal{F}$ Physiol 1986;250:G244-7.

30 Camilleri M, Brown ML, Malagelada J-R. Relationship between impaired gastric emptying and abnormal gastrointestinal motility. Gastroenterology 1986;91:94-9.

31 Behar J, Ramsby G. Gastric emptying and antral motility in reflux esophagitis - effect of oral metoclopramide. Gastroenterology 1978;74:253-6.

32 Johnson AG. The effects of cisapride on antroduodenal co-ordination and gastric emptying. Scand $\mathcal{F}$ Gastroenterol 1989;24(suppl 165):36-43

33 Schuurkes JAJ, Helsen LFM, Ghoos ECR, et al. Stimulation of gastroduodenal motor activity: dopaminergic and cholinergic modulation. Drug Development Research 1986;8: $233-41$. 